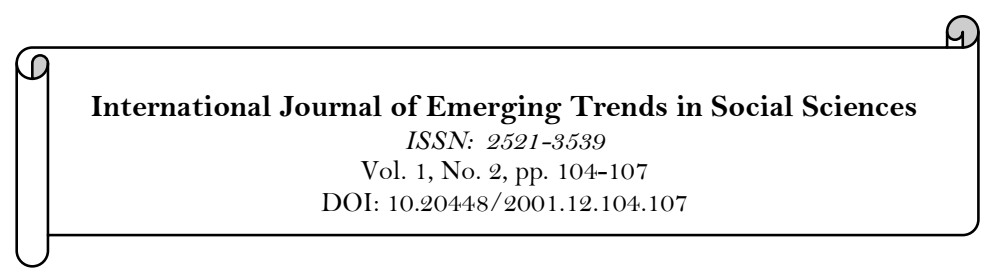

\title{
Pregnant Women with Extended Family on Knowledge, Motivation, and Readiness In Exclusive Breastfeeding
}

\author{
Sri Mulyani ${ }^{1}$ \\ 'Faculty of Medicine, Sebelas Maret University, Indonesia.
}

\begin{tabular}{|c|c|}
\hline Abstract & \\
\hline $\begin{array}{l}\text { Family support has a relationship with the successful exclusive } \\
\text { breastfeeding, because of the presence of the family is very important } \\
\text { to encourage mothers to boost confidence and stabilize emotions. } \\
\text { Demographic factors such as residence status of pregnant women } \\
\text { whether live with in-laws family (extended family) or nuclear family } \\
\text { (nuclear family) will affect the readiness of mothers in exclusive } \\
\text { breastfeeding. This study aims to determine whether there is } \\
\text { influence of the residence status toward knowledge, motivation, and } \\
\text { readiness of mothers in exclusive breastfeeding. Cross-sectional } \\
\text { study performed on pregnant women in Surakarta. A sample of } 150 \\
\text { respondents was taken under observation in 2015. Various } \\
\text { demographic characteristics, knowledge, motivation, and readiness of } \\
\text { mothers in exclusive breastfeeding, measured with a structured } \\
\text { questionnaire. Statistical analysis techniques used independent } \\
\text { samples t-test and multiple linear regressions. The results showed } \\
\text { that the residence status did not affect mothers knowledge on } \\
\text { exclusive breastfeeding. Pregnant women who chose to live only } \\
\text { with husband (nuclear family) had the significant motivation and } \\
\text { readiness of exclusive breastfeeding significantly. Based on a } \\
\text { multivariate model proved that the motivation and better } \\
\text { preparedness in fact due to the higher education level. Nevertheless } \\
\text { the results of this study indicate a significant effect on mothers' } \\
\text { residence status on motivation exclusive breastfeeding. }\end{array}$ & $\begin{array}{l}\text { Licensed: } \\
\text { This work is licensed under a } \\
\text { Creative Commons Attribution } \\
\text { 4.0 License. } \\
\text { Publisher: } \\
\text { Scientific Publishing Institute }\end{array}$ \\
\hline
\end{tabular}

\section{Introduction}

Cultural background of the local community is very influential in the implementation of exclusive breastfeeding, things that need to be considered include: perceptions, habits, patterns of infant feeding in local community, the notion that breastfeeding is a very simple thing, not an instinct but it is an art / culture inherited from mother to daughter (Azwar, 2008). Rural and urban environments sometimes differ from culture. According to Bobak and Jansen (2005) in the countryside feeding habits of children is a tradition while urban accustom to a formula milk with a more modern and practical considerations. Urban people never see a model of exclusive breastfeeding from the environment, this condition later affects the mother in taking a stand for exclusive breastfeeding. In addition in-law family has a strong influence on the process of breastfeeding because newly mother will normally follow the advice of their relatives.

Women / mothers have a strategic role in the family and society, namely as a fortress to protect their son also serve as an initiator to raise awareness about the importance of exclusive breastfeeding for the future quality of human resources in the Ministry of Health (2008). Ohnishi, Kakamura, and Takano (2005) finds that mothers who have better literacy maternal health will less likely fail in exclusive breastfeeding, compared to the group with lower health literacy, while Notoatmodjo (2003) states that knowledge is the result from the idea, and this occur after people perform sensing to a particular object. Knowledge is an important domain in shaping a person's actions.

According to Azwar (2008) along with times, there is also rapid increasing in science and technology. Ironically, the previous knowledge such as breastfeeding is sometimes forgotten. According to Renkert and Nutbeam (2001) the loss of knowledge in breastfeeding is a great loss, because breastfeeding is a knowledge that important role for million years in sustaining human life, and therefore it needs the support of various parties, husband's family, parents, in-laws, brother, sister and brother. One way to form family support is in 
material or physical assistance or others to support and assist pregnant mothers to be ready for exclusive breastfeeding (Black, Jarman, \& Simpson, 1998).

Motivation can be defined as the power (energy), how strong the motivation of the individual will determine the behavior in reality. Mothers are given situation either to breastfeed or not to do so. Although for many women this is not an option but an obligation, however, a mother should take the decision to breastfeed or otherwise and will provide exclusive breast milk or not. The decision of giving breastfeeding is usually taken days away before giving birth and even before marriage, as the opinion Katherine, Ruowei, Benton, and Grummer (2005) states that the decision to breastfeed or not to is performed even before pregnancy. According to Purwanti (2004) preparation of breastfeeding during pregnancy is important, mothers who prepare early will be well prepared to breastfeed and get optimal quality and quantity.

\section{Method}

Cross-sectional study performed on pregnant women who live in Surakarta. During the observation in 2015, 150 respondents were takes as respondents. Mother's knowledge, motivation and readiness on exclusive breastfeeding were measured with a structured questionnaire (Creswell, 2012; Effendi, 2014; Mardikanto, 2012) Each of these concepts or variables were measured by several items of questions that previously had been validated both in terms of language or sentence structure (content validity) as well as construct. All constructs (variables) also has a high reliability (Cronbach's alpha> 0.9). Data is also collected various characteristics of respondents, including age, education, occupation, time of marriage, the distance of a residence with a health facility, and residency status (husbands or parents / in-laws residency). Data were analyzed by using bivariate with independent samples t-test and multivariate multiple linear regression. Data processing was performed using SPSS for Windows version 13. Statistical testing was conducted with a significance level of $5 \%$.

\section{Result}

The identification result of residency status indicates that 56 respondents $(37.3 \%)$ lived only with her husband and 94 respondents (62.7\%) lived with husband and parents (in-laws). Characteristics of age were equally distributed in both groups $(\mathrm{p}=0.386)$. The characteristics of education and employment status are not the case. Group of respondents who lived only with husband had a level of significant education $(p=0.008)$ compared to the group of respondents who lived with husband and parents (in-law). Group of respondents who lived only with husband, significantly stayed at home $(p=0.001)$ than the group of respondents who lived with husband and parents (in-law). Description of the characteristics of respondents is drawn in Table 1.

Table-1. Description of Respondents Characteristics.

\begin{tabular}{l|l|l|l}
\hline Characteristic & $\begin{array}{l}\text { Live with Husband } \\
(\mathrm{n}=56)\end{array}$ & $\begin{array}{l}\text { Live with Husband } \\
\text { \&Parents/In-laws } \\
(\mathrm{n}=94)\end{array}$ & $\mathbf{P}$ \\
\hline Age & $1(1,8 \%)$ & $10(10,6 \%)$ & \\
$16-20$ & $38(67,9 \%)$ & $58(61,7 \%)$ & 0,386 \\
$21-25$ & $17(30,4 \%)$ & $21(22,3 \%)$ & \\
$26-30$ & $0(0,0 \%)$ & $2(3,2 \%)$ & \\
$31-35$ & $0(0,0 \%)$ & $2,1 \%)$ & $0,008^{*}$ \\
$36-40$ & & $2(2,1 \%)$ & \\
Education & $0(0,0 \%)$ & $18(19,1 \%)$ & \\
Elementary & $8(14,3 \%)$ & $19(20,2 \%)$ & \\
Junior High School & $24(42,9 \%)$ & & $0,001^{*}$ \\
Senior High School & $24(42,9 \%)$ & $63(67,0 \%)$ & \\
Collage & & $31(33,0 \%)$ & \\
\hline Occupational Status & $22(39,3 \%)$ & & \\
Employed & $34(60,7 \%)$ & & \\
Unemployment & & & \\
\hline Keterangan: * $<0,05$. & & & \\
& & & \\
\end{tabular}

In Table 2 shows the results of comparative calculations score of knowledge, motivation, and readiness among respondents who live only with husband and respondents who live with husband and parents (in-law). Scores of respondents' knowledge living with their husbands were only relatively lower than the score of respondents' knowledge living with husband and parents (in-law). Despite difference in scores was not significant $(p=0.289)$ this concluded there was no difference of knowledge about exclusive breastfeeding to their residency status. Respondents who lived only with husband has a motivation score $(p=0.013)$ and readiness $(p=0.019)$ was significantly higher than those respondents who lived with husband and parents (in- 
law). This shows that a pregnant woman who live only with husbands tend to have motivation and readiness to give exclusive breastfeeding.

The conclusion drawn by Table 2 had a potential bias considering the state of the characteristics of respondents which were not homogenous between the two groups. As Table 1 showed, respondents who lived only with husbands have a higher level of education and tend to be unemployment. Therefore, further analysis using a multivariate linear regression model to include residency status, characteristics of education and employment status as a predictor of motivation and readiness to give exclusive breastfeeding.

Tablel-2. Result of Multivariate Analysis.

\begin{tabular}{|c|c|c|c|}
\hline Dependent Variable & Predicator & B & $\mathbf{P}$ \\
\hline $\begin{array}{l}\text { Motivation to give exclusive } \\
\text { breastfeeding }\end{array}$ & $\begin{array}{l}\text { Education } \\
\text { Employment } \\
\text { Residency Status }\end{array}$ & $\begin{array}{l}0,323 \\
-0,053 \\
0,148\end{array}$ & $\begin{array}{l}<0,001 \\
0,523 \\
0,070\end{array}$ \\
\hline $\begin{array}{l}\text { Readiness to give exclusive } \\
\text { breastfeeding }\end{array}$ & $\begin{array}{l}\text { Education } \\
\text { Employment } \\
\text { Residency Status }\end{array}$ & $\begin{array}{l}0,140 \\
0,120 \\
0,129\end{array}$ & $\begin{array}{l}0,096 \\
0,161 \\
0,126\end{array}$ \\
\hline
\end{tabular}

Information: * $\mathrm{p}<0,05$

In Table 2 can be viewed that the results of the multivariate analysis prove the existence of bias conclusions bivariate analysis Table 2. After entering the educational level and employment status as covariates in the multivariate linear regression model, factors unrelated residency status became significant for both the motivation and the readiness to give exclusive breastfeeding. Only significant level of education was related to motivation $(p<0.001)$ and only marginally related to the readiness $(p=0.096)$. This shows (totally summed with results in Table 1 that a higher motivation and (or possibly) better preparedness of pregnant women who live only with her husband is actually caused due to a higher level of education. Nonetheless it found also marginal relationship between the status of living with motivation $(p=0.070)$. This indicates a possible influence on the motivation residency status because of the level of education.

\section{Discussion}

The concept of this study is based on a theory proposed by Mann, Reifsnider, Gill, and Retsema (2003) that the exclusive breastfeeding process is influenced by several factors: internal factors and external factors of the mother. Some of the factors of the mother include: (1) the level of knowledge about breastfeeding, (2) confidence and (3) employment. External factors that influence are: (1) health institutions, (2) the general public, (3) the closest family circle. A mother company in daily shows close family environment directly and intensely affected exclusive breastfeeding. The presence of parents or in-laws at home can have a positive influence because they can pass on their knowledge and experience in nursing and provide support so that it will increase the motivation and readiness of mothers in exclusive breastfeeding.

In particular culture of society in which the parents or in-laws staying at home can affect negatively when their own basically do not have a good understanding about exclusive breastfeeding or are still bound by tradition or habit that may be less precise in the community. The study provides an overview of how women (and generally also husband) with high education tend to choose to live separately from their parents and inlaws. The selection appears to be a positive impact for the reasons one parent or in-law is not directly teach or even impose customs or traditions that are less precise regarding to breastfeeding. Only empirical effect of the presence or absence of parents or in-laws has not been proven. This study clearly only proves that the high motivation of pregnant women in exclusive breastfeeding is the positive influence of a high level of education is similar to case studies (Binns et al., 2004).

However in spite of the definite conclusions obtained, the study also gives an indication of the possibility of residency status influence by only with the husband or the parents (in-law) to motivate pregnant women to give exclusive breastfeeding. This will require further research to explain how a mother living with husband just tends to have a higher motivation in exclusive breastfeeding than live well with parents or in-laws. It is expected more and clearly identified factors in the future that can affect the motivation and readiness of pregnant women in exclusive breastfeeding.

\section{Conclusion}

Based on the results of this study can be concluded that residency status does not affect the mother's knowledge on exclusive breastfeeding. Pregnant women who live only with husband have significant motivation and readiness of exclusive breastfeeding. It is based on a multivariate model proved that better motivation and readiness due to the higher education level. Nevertheless the results of this study indicate the influential possibility of residency status on pregnant women motivation in exclusive breastfeeding. 


\section{References}

Azwar, A. (2008). Normal childbirth care and early breastfeeding initiation. Jakarta: JNPK-KR.

Binns, C., Gilchrist, D., Gracey, M., Zhang, M., Scott, J., \& Lee, A. (2004). Factors associated with the initiation of breastfeeding by Aboriginal mothers in Perth. Public Health Nutrition, 7(7), 857-861.

Black, R. F., Jarman, L., \& Simpson, J. (1998). Lactation specialist series module self study: The support of breastfeeding. Sudbury, MA: Jones \& Bartlett.

Bobak, L., \& Jansen. (2005). Maternity nursing textbook (4th ed.). Jakarta: EGC.

Creswell, J. W. (2012). Research design qualitative, quantitative and mixed approaches. Yogjakarta Student Library.

Effendi, S. T. (2014). Research method revised edition survey. Jakarta: LP3ES Publisher.

Katherine, R. S., Ruowei, L., Benton, D., \& Grummer, S. (2005). The CDC guide to intervention breastfeeding. U.S Department of Health \& Human Services Center for Disease Control and Prevention of the National Center for Electronic Disease Prevention and Health Promotion Division of Nutrition and Physical Activity.

Mann, A. R., Reifsnider, E., Gill, S. L., \& Retsema, M. (2003). Health disparities in low income and hispanic women breastfeeding. Journal of Multicultural Nursing $\mathcal{E}^{2}$ Health, 9(3), 49-56.

Mardikanto, T. (2012). Research methods and evaluation of community empowerment, extension program for community development. Empowerment of the Sebelas Maret University Surakarta Program.

Notoatmodjo, S. (2003). Health education and behavior. Jakarta: Creative design, 16, 15-49.

Ohnishi, M., Kakamura, K., \& Takano, T. (2005). Improvement in maternal health literacy among pregnant women who are not complete compulsory education: Policy implications for community care services. Health Policy, 72(1), $157-164$.

Purwanti, H. S. (2004). Exclusive breastfeeding concept. Jakarta: EGC.

Renkert, S., \& Nutbeam, D. (2001). Opportunities to improve maternal health literacy through antenatal education: An exploratory study. Health Promotion International Journal, 16(4), 381-388. 